\title{
Bevacizumab-based first-line chemotherapy in elderly patients with metastatic colorectal cancer: an individual patient data based meta-analysis
}

\author{
Christine Koch ${ }^{1}$, Anna M. Schwing ${ }^{1}$, Eva Herrmann ${ }^{2}$, Markus Borner ${ }^{3}$, Eduardo \\ Diaz-Rubio', Efrat Dotan5, Jaime Feliu', Natsuko Okita7, John Souglakos ${ }^{8}$, Hendrik \\ T. Arkenau ${ }^{9}$, Rainer Porschen ${ }^{10}$, Miriam Koopman ${ }^{11}$, Cornelis J.A. Punt ${ }^{12}$, Aimery \\ de Gramont ${ }^{13}$, Christophe Tournigand ${ }^{14}$, Stefan Zeuzem ${ }^{1}$ and Joerg Trojan ${ }^{1}$ \\ ${ }^{1}$ Department of Gastroenterology, University Liver and Cancer Centre, Frankfurt, Germany \\ ${ }^{2}$ Institute of Biostatistics and Mathematical Modelling, Johann Wolfgang Goethe-University, Frankfurt, Germany \\ ${ }^{3}$ Medical Oncology Institute, Inselspital, Bern, Switzerland \\ ${ }^{4}$ Department of Oncology, Hospital Clínico San Carlos, Madrid, Spain \\ ${ }^{5}$ Fox Chase Cancer Center, Philadelphia, PA, USA \\ ${ }^{6}$ Department of Medical Oncology, La Paz University Hospital, CIBERONC, Madrid, Spain \\ ${ }^{7}$ National Cancer Center, Tokyo, Japan \\ ${ }^{8}$ Department of Medical Oncology, University Hospital of Heraklion, University of Crete, Crete, Greece \\ ${ }^{9}$ Sarah Cannon Research Institute, London, UK \\ ${ }^{10}$ Klinikum Bremen Ost, Bremen, Germany \\ ${ }^{11}$ Department of Medical Oncology, University Medical Centre, Utrecht, The Netherlands \\ ${ }^{12}$ Department of Medical Oncology, Academic Medical Center, University of Amsterdam, Amsterdam, The Netherlands \\ ${ }^{13}$ L'Institut Hospitalier Franco-Britannique, Paris, France \\ ${ }^{14}$ University of Paris Est Creteil, Henri-Mondor Hospital, Créteil, France \\ Correspondence to: Joerg Trojan, email: Trojan@em.uni-frankfurt.de \\ Keywords: metastatic colorectal cancer; elderly; first-line chemotherapy; bevacizumab
}

Received: June 12, $2017 \quad$ Accepted: December 08, $2017 \quad$ Published: December 20, 2017

Copyright: Koch et al. This is an open-access article distributed under the terms of the Creative Commons Attribution License 3.0 (CC BY 3.0), which permits unrestricted use, distribution, and reproduction in any medium, provided the original author and source are credited.

\section{ABSTRACT}

Background: The aim of this meta-analysis was to evaluate efficacy and safety of first-line chemotherapy with or without a monoclonal antibody in elderly patients ( $\geq 70$ years) with metastatic colorectal cancer ( $\mathrm{mCRC}$ ), since they are frequently underrepresented in clinical trials.

Results: Individual data from 10 studies were included. From a total of 3271 patients, 604 patients (18\%) were $\geq 70$ years (median 73 years, range $70-88$ ). Of these, 335 patients were treated with a bevacizumab-based first-line regimen and 265 were treated with chemotherapy only. The median PFS was 8.2 vs. 6.5 months and the median OS was 16.7 vs. 13.0 months in patients treated with and without bevacizumab, respectively. The safety profile of bevacizumab in combination with first-line chemotherapy did not differ from published clinical trials.

Materials and Methods: PubMed and Cochrane Library searches were performed on 29 April 2013 and studies published to this date were included. Authors were contacted to request progression-free survival (PFS), overall survival (OS) data, patient data on treatment regimens, age, sex and potential signs of toxicity in patients $\geq 70$ years of age.

Conclusions: This meta-analysis suggests that the addition of bevacizumab to standard first-line chemotherapy improves clinical outcome in elderly patients with MCRC and is well tolerated. 


\section{INTRODUCTION}

Colorectal cancer (CRC) is one of the most common cancers worldwide with over 1,300,000 new cases each year [1]. The incidence rate of colorectal cancer increases with age, rising from 8.4 per 100,000 at age $40-44$ years to 127.8 per 100,000 at age $70-74$ years and 196.2 per 100,000 at $\geq 75$ years [1]. In Europe alone, over 300,000 new patients are diagnosed annually [1] and more than $61 \%$ of these patients are $\geq 70$ years of age [2].

Fluoropyrimidines, irinotecan and oxaliplatin are the standard cytotoxic agents used in the treatment of metastatic colorectal cancer (mCRC). Survival benefit with standard chemotherapy regimens has been shown to be similar for $\mathrm{mCRC}$ patients $\geq 70$ years of age compared with those $<70$ years, and there is no marked difference in tolerability profiles [3].

Since elderly patients are more likely to suffer from comorbidities and to present with age-related decline in organ function (especially liver, kidney and bone marrow) than younger patients, there is an under-representation of elderly patients in cancer treatment trials, with $<10 \%$ of patients enrolled in colorectal cancer clinical trials being $>70$ years of age [4-6]. For CRC trials, the median age of patients is 63 years, while the median age of patients at diagnosis of CRC is 72 years [1]. As a result of this, findings from colorectal clinical trials do not necessarily fully reflect real-life experience as the proportion of elderly patients is low and any subgroup analysis evaluating treatment efficacy in elderly patients from a single trial is difficult to perform with sufficient power because of this low number of patients. One phase III clinical trial that evaluated bevacizumab plus capecitabine versus capecitabine alone elderly patients with previously untreated mCRC was the AVEX trial [7], which found the bevacizumab plus capecitabine combination to be effective and well tolerated. Apart from AVEX, no further randomized studies addressing this sometimes more fragile population are available. Besides, some small cohort or single-arm studies enrolling elderly patients suggested that these patients also benefit from the addition of bevacizumab to standard chemotherapy $[8,9]$. Metaanalysis of a number of similar clinical trials is an option to allow analysis of a sufficient amount of clinical data.

Treatment guidelines can vary considerably (go/ go slow/no go) for elderly patients, and comprehensive geriatric assessment is rarely implemented in clinical practice $[10,11]$. Therefore, because of the relative lack of clinical data in elderly patients with CRC, clinical decision making is driven by the assumed outcome and the assumed safety and tolerability.

The efficacy of standard chemotherapy regimens can be further improved with either the combination with bevacizumab, a humanized monoclonal antibody against vascular endothelial growth factor (VEGF), or with the epithelial growth factor receptor antibodies cetuximab or panitumumab in patients with RAS wild-type tumors [12]. As a result of the benefits observed with these regimens in controlled clinical trials, it is of critical importance to determine how the elderly mCRC population responds to and tolerates such treatment regimens.

The aim of this meta-analysis was to combine data from a number of clinical trials to evaluate the efficacy and safety of first-line chemotherapy with or without a monoclonal antibody in elderly patients ( $\geq 70$ years of age) with mCRC.

\section{RESULTS}

\section{Literature search results}

Overall, 1063 potential publications were identified on the PubMed and Cochrane databases; of these, 867 were excluded based on reading the title, the abstract or being duplicates, leaving 196 articles to be read completely. Of these 196 articles, 43 fulfilled the inclusion and exclusion criteria and 3 further studies were identified; hence, 46 authors and three pharmaceutical companies were contacted for individual study data. In total, we received primary data from 10 studies [13-22] with different chemotherapeutic agents or regimens, all of them were from cooperative groups only. The chemotherapy backbone included infusional 5FU or capecitabine based combination regimens with either oxaliplatin or irinotecan \pm bevacizumab (Table 1; Figure 1). From 8 trials complete datasets were analysed [14-21]. From two studies, safety data were not available for analysis [13, 22]. All studies included had been approved by ethical committees.

\section{Outcomes}

The 10 studies from which we received primary data included a total of 3271 patients, of which 604 patients (18\%; ranging from between 1 and 139 patients per study) were 70 years or older and were included in the dataset (Table 1). Across all patients included in the meta-analysis, $375(62.6 \%)$ were male and the median age was 73 years (range 70-88 years). There was no significant difference ( $p$ $>0.20$ ) in patients' age distribution between those treated with or without bevacizumab (Supplementary Figure 1). In total, 335 patients were treated with a bevacizumabbased first-line regimen and 264 patients were treated with chemotherapy only. Since only 5 patients were treated with a cetuximab-based first-line regimen, this group was excluded from further analysis.

\section{Primary analysis}

Median follow-up time ranged from 7.4 months to 23.4 months in the single studies. For the primary outcomes of PFS and OS, there was a high degree of heterogeneity between the sites; Figure 2 shows the 
overall summary curves derived from Cox regression for PFS and OS for patients $\geq 70$ years of age treated with or without bevacizumab and also displays the Kaplan-Meier survival curves from the individual study arms. Both PFS and OS were significantly increased in patients receiving chemotherapy with bevacizumab (PFS: HR 1.39, 95\% CI $1.14-1.70 ; p=0.0014$; OS: HR 1.29, 95\% CI 1.04-1.60; $p=0.019$ ). The median PFS was 8.2 vs. 6.5 months, the median OS was 16.7 vs. 13.0 months in patients treated with and without bevacizumab, respectively. For both PFS and OS, variance of the random effect terms was 0.004 . Forest plots of PFS and OS rates at 12, 24, 36 and 48 months from the individual studies in patients $\geq 70$ years of age treated with or without bevacizumab show variation with and between studies (Figures 3 and 4).

Assessment of potential risk of selection or publication bias across the studies also used PFS and OS rates at 12, 24, 36 and 48 months. Funnel plots for PFS and OS rates at 12 months showed no signs of asymmetry $(p=0.20$ and $p>0.20$, respectively; see Supplementary Figure 2), which would indicate the absence of selection bias. A sensitivity analysis was also performed to determine whether the results in controlled but nonrandomised studies differed from those of randomised studies - this correction for study type was not statistically significant and the HR of bevacizumab treatment changed only marginally.

\section{Additional analyses}

Further analyses were performed evaluating the influence of age, sex and a number of other factors included in the dataset on OS and PFS with the corresponding Cox regression models including these factors or covariates as well as a frailty term to account for heterogeneity. The strongest association for both PFS and OS was found to be

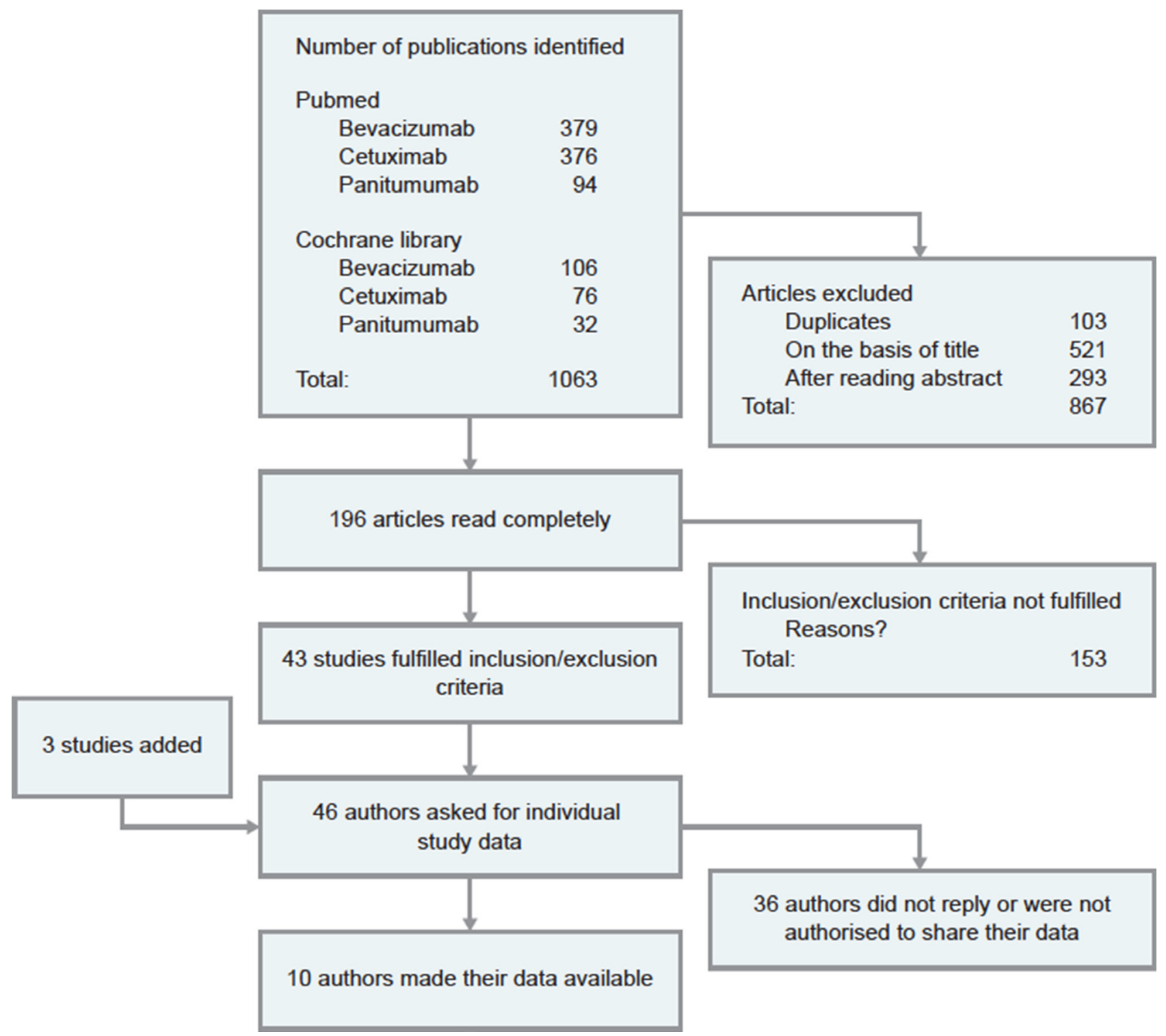

Figure 1: CONSORT flow diagram. 
age ( $p=0.0210$ and $p<0.0001$, respectively; Figure 5), bleedings of grade 3 or $4(p=0.0112$ and $p=0.0005$, respectively) and hand-foot syndrome $(p=0.007$ and $p=$ 0.025 , respectively). Multivariate analyses confirmed that treatment with bevacizumab significantly increased PFS and OS compared with chemotherapy treatment only ( $p=0.0048$ and $p=0.0016$, respectively; Supplementary Table 1).

Comparison of frequencies of markers of toxicity between study arms of patients treated with and without antibodies found that there was no significant difference of toxicities in patients treated with bevacizumab than without (Table 2; Supplementary Figure 3).

\section{DISCUSSION}

Elderly patients are often underrepresented in oncological clinical trials. However, the majority of colorectal cancers arise in patients older than 70 years $[1$, 2]. As the population at least in western countries ages, the term "elderly" needs to be better defined, since it is evident that there is a wide range in the performance status of different patients of the same age. Geriatric assessments are a tool to evaluate and manage functional and cognitive impairments in elderly oncologic patients [28] and should be implemented in daily practise as well as in clinical trials to better distinguish between "fit" and "frail".

The aim of the study was the assessment of both PFS and OS in patients $\geq 70$ years of age treated with chemotherapy with or without a monoclonal antibody. More recently, primary tumor location, RAS and BRAF status were established as important prognostic factors for colorectal cancer patients [28, 29, 30, 31]. However, since our data set was based on studies published until April 2013, we did not address these prognostic factors in our analysis.

The results of this meta-analysis show that both PFS and OS were significantly increased in elderly patients with $\mathrm{mCRC}$ receiving chemotherapy plus bevacizumab compared with those receiving chemotherapy alone (Figure 2A, 2B), and there would appear to be a lack of selection bias in this finding. As would be anticipated in an elderly population, PFS and OS were influenced by age with both outcomes being greater in the 'younger' population (Figure 5); the population that would be anticipated to have prolonged survival in a disease-free state. A finding that was observed in the BRiTE observational cohort study, in which patients $\geq 65$ years of age and receiving
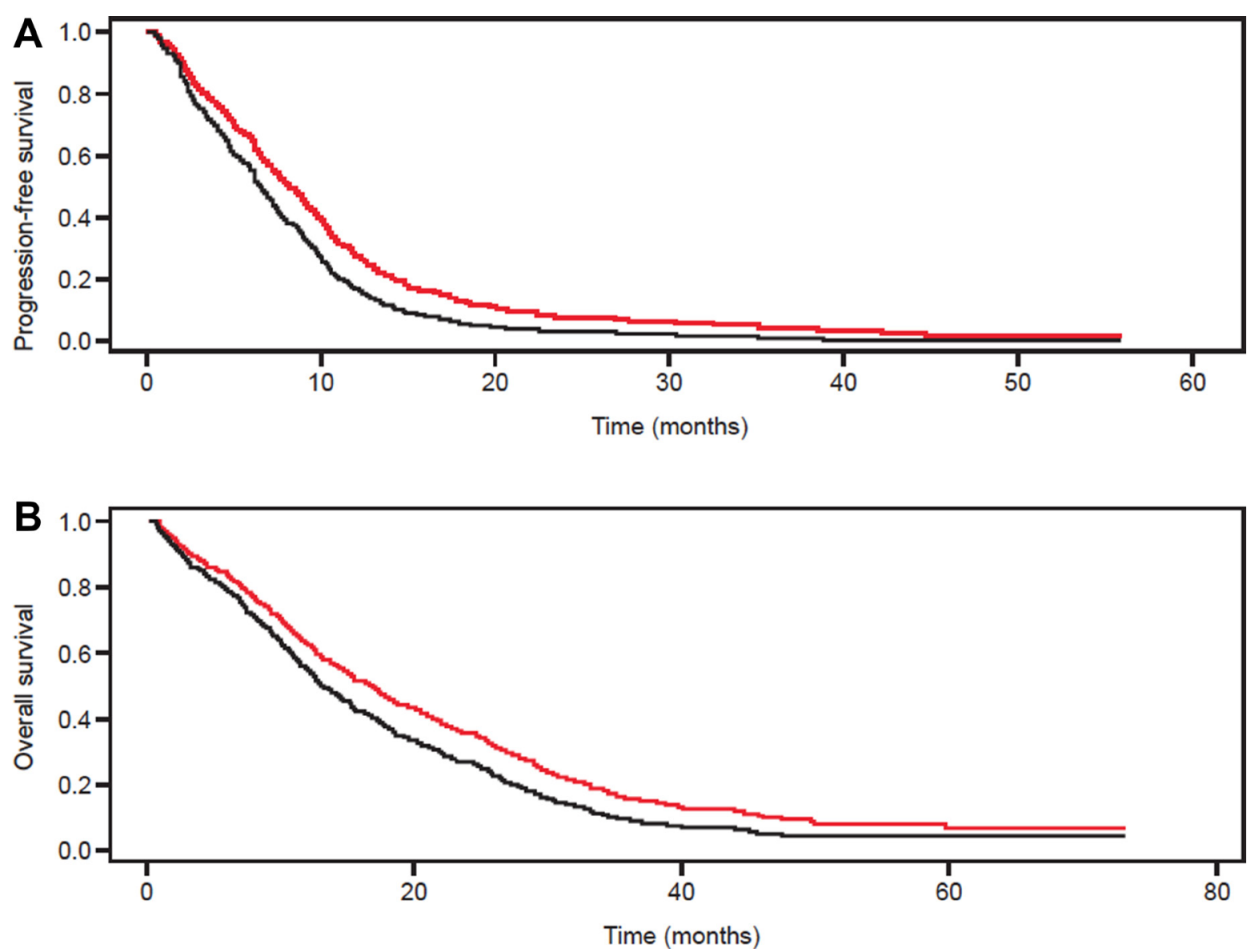

Figure 2: (A) Progression-free survival and (B) overall survival in patients $\geq 70$ years of age with mCRC treated with standard chemotherapy with (red lines) or without (black lines) bevacizumab in the single study populations. Displayed is the summary estimation from a Cox regression with frailty approach. The median PFS was 8.2 vs. 6.5 months and the median OS was 16.7 vs. 13.0 months in patients treated with and without bevacizumab, respectively. 
Progression-free survival rate at 12 months

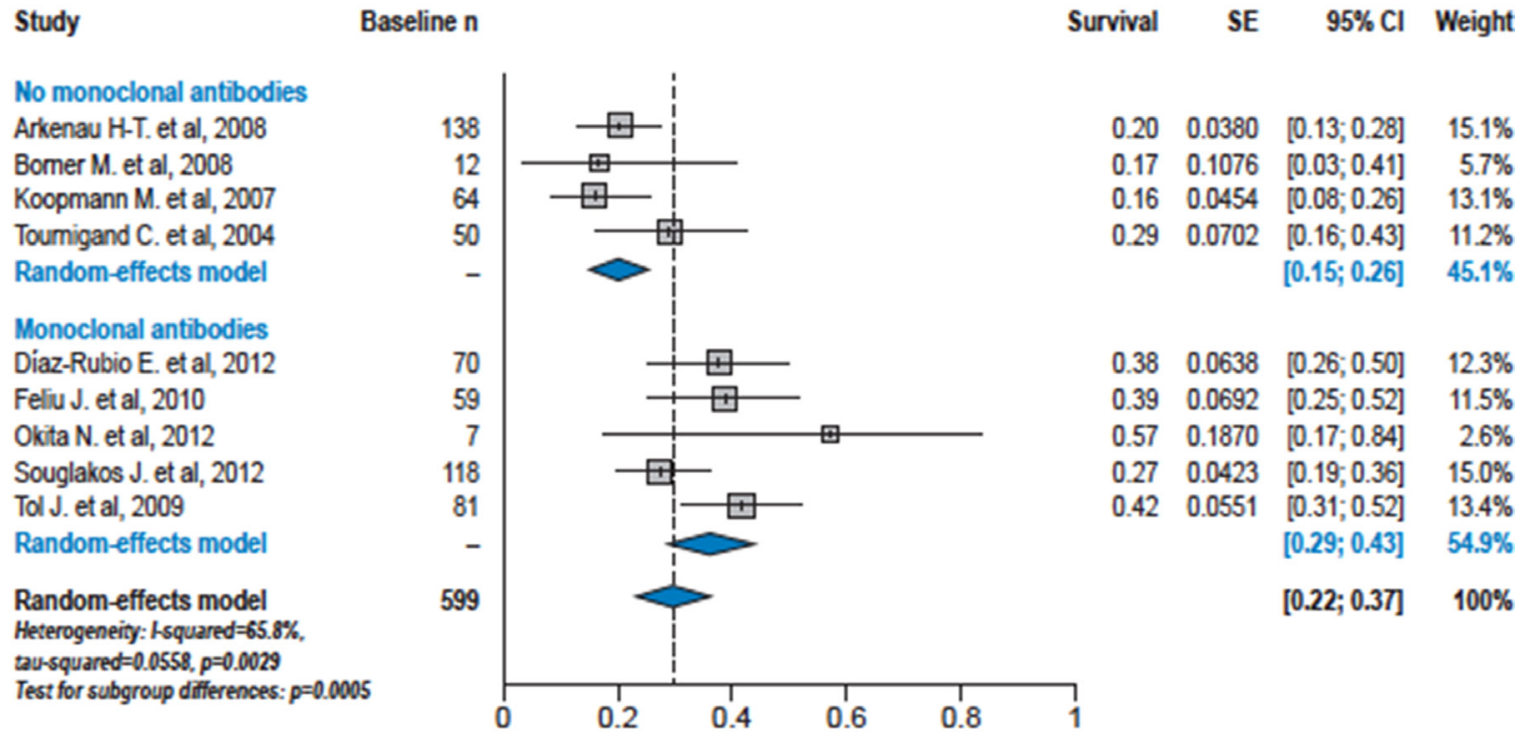

Progression-free survival rate at 24 months

Study

No monoclonal antibodies

Arkenau H-T. et al, 2008

Koopmann M. et al, 2007

Toumigand C. et al, 2004

Random-effects model

Monoclonal antibodies

Diaz-Rubio E. et al, 2012

Souglakos J. et al, 2012

Tol J. et al, 2009

Random-effects model

Random-effects model

Heterogeneiry: Lsquared $=0 \%$,

tau-squared $=0, p=0.5042$

Test for subgroup differences: $p=0.3432$

\section{Baseline $\mathrm{n}$}

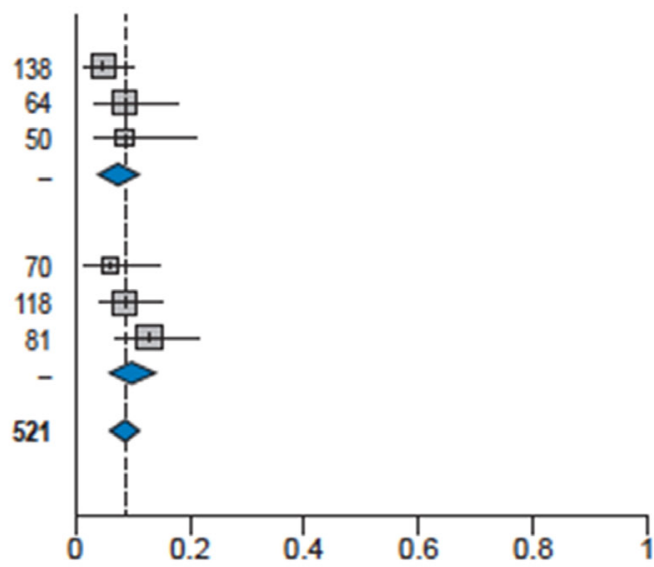

Survival SE $\quad 95 \% \mathrm{Cl}$ Weight

$\begin{array}{rrrr}0.05 & 0.0220 & {[0.01 ; 0.10]} & 17.9 \% \\ 0.09 & 0.0364 & {[0.03 ; 0.18]} & 15.4 \% \\ 0.09 & 0.0486 & {[0.03 ; 0.21]} & 9.2 \% \\ & & {[0.04 ; 0.11]} & 42.5 \% \\ & & & \\ & & & \\ 0.06 & 0.0332 & {[0.02 ; 0.15]} & 11.3 \% \\ 0.09 & 0.0282 & {[0.04 ; 0.15]} & 25.0 \% \\ 0.13 & 0.0382 & {[0.07 ; 0.21]} & 21.2 \% \\ & & {[0.06 ; 0.14]} & 57.5 \% \\ & & {[0.06 ; 0.11]} & 100 \%\end{array}$

$\begin{array}{llll}0.05 & 0.0220 & {[0.01 ; 0.10]} & 17.9 \%\end{array}$

$0.09 \quad 0.0364 \quad[0.03 ; 0.18] \quad 15.4 \%$

$[0.03 ; 0.21] \quad 9.2 \%$

$[0.06 ; 0.11] \quad 100 \%$

Progression-free survival rate at 36 months

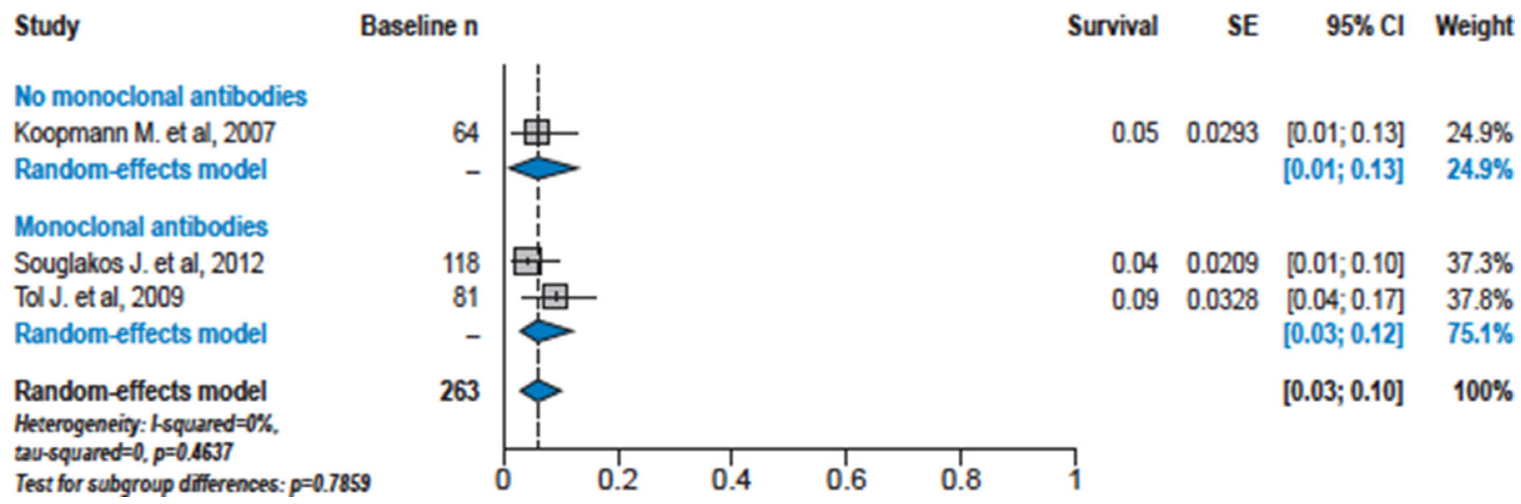

Figure 3: Forest plots of progression-free survival rates at 12, 24 and 36 months from the individual studies in patients $\geq 70$ years of age treated with or without bevacizumab. For each study arm, survival rates and standard error are derived by single nonparametric Kaplan-Meier estimates. 
stuty

No monocional antibodles Ahenay H-T. et a, 2008 Bomer $M$ et al, 2008 Koopram M et a., 2007 Toumignd C. ef al, 2004 Randomeflacts model

Monodional antbodies Disz-Pubio et a, 2012 Felu J et a, 2010 Oxtan. et al, 2012

Sougakos J. et a, 2012 Tod J. et a., 2009 Randomenteds model Randomerlects model Harogenely: hequmden.s.

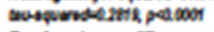
Tour for aud prop difnecen: pesew

Baseline n

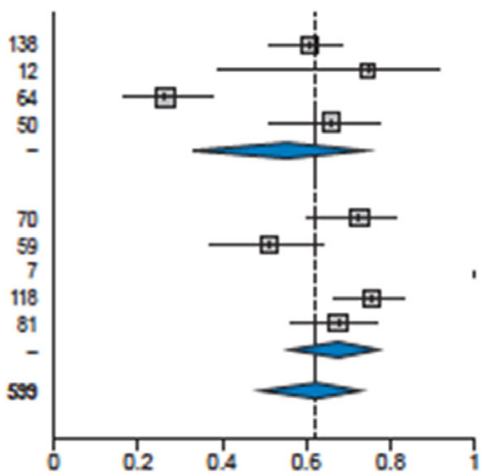

Survial SE 95\%, Whight

$0.610 .04270 .520 .68] 14.1 \%$

$0.740 .1266[0.39,0.91] \quad 6.9 \%$

$0.270 .0652 \quad 0.16 ; 0.387 \quad 139 \%$

$0.660 .0670 \quad 0.51 ; 0.77] \quad 12.5 \%$

[0.53;0.74] $47.4 \%$

$0.720 .0637 \quad 0.60 ; 0.81] \quad 127 \%$

$0.51 \quad 0.0684 \quad 0.37,0.64] \quad 13.2 \%$

100

$\begin{array}{llllll}0.76 & 0.0908 & 0.67 & 0.83 & 13.4 \%\end{array}$

$0.680 .0621 \quad[0.56 ; 0.77] \quad 13.3 \%$

$[0.56,0.77] 52.6 \%$

$[0.8 ; 0.73] 100 \%$

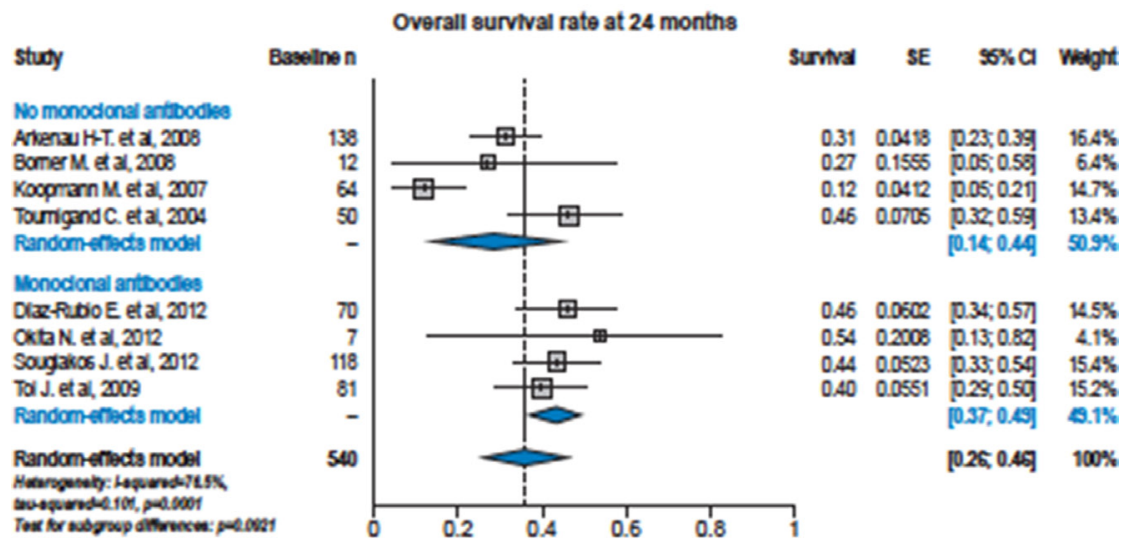

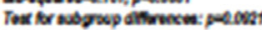

Overall survival rate at 36 months

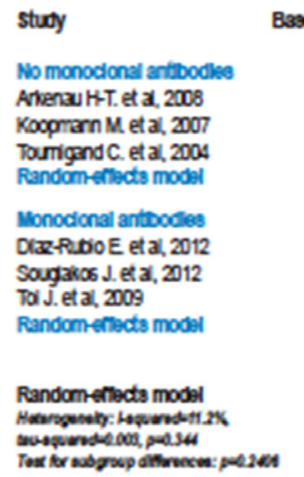

Bsseltnen

Sumva SE $95 \% \mathrm{Cl}$ waght.

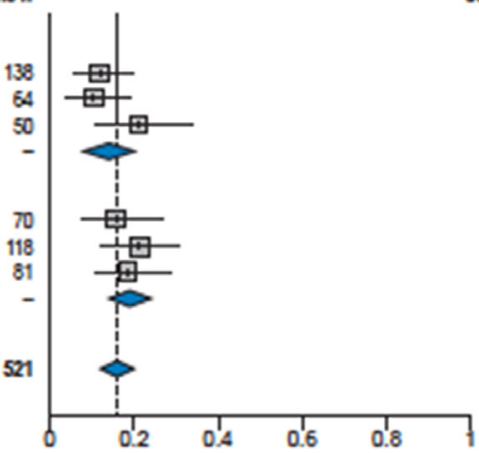

$0.110 .035 \quad 0.05 \% 0.29 \quad 19.1 \%$

$0.10 \quad 0.03 \%$ p.04;0.19 $148 \%$

0.210 .0588 [0.11:0.39] $13.0 \%$

$0.160 .04850 .05,0.29 \quad 145 \%$

$0.210 .040 \quad$ p.12;0.31] $19.0 \%$

0.190 .045 [0.11;0.28] $19.6 \%$

$[0.140 .24] 53.1 \%$

$[0.12 \div 0.20] \quad 100 \%$

Overall survival rate at 48 months
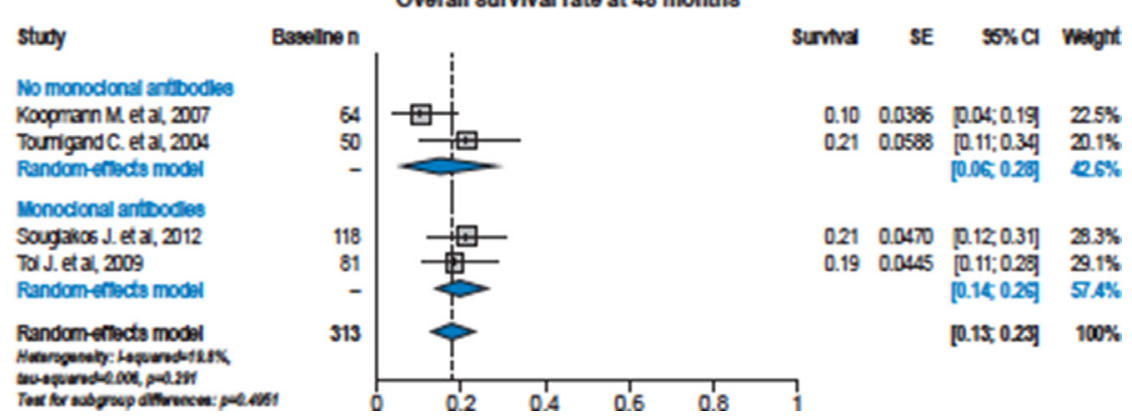

Figure 4: Forest plots of overall survival rates at 12, 24, 36 and 48 months from the individual studies in patients $\geq$ 70 years of age treated with or without bevacizumab. For each study arm, survival rates and standard error are derived by single nonparametric Kaplan-Meier estimates. 
Table 1: Summary of studies included in the meta-analysis

\begin{tabular}{|c|c|c|c|c|c|}
\hline Author & Regimens & $\begin{array}{c}\text { Elderly } \\
\text { patients/ } \\
\text { total patients }\end{array}$ & $\begin{array}{l}\text { Primary } \\
\text { endpoint }\end{array}$ & Secondary endpoints & Reference \\
\hline Borner 2008 & $\begin{array}{l}\text { Capecitabine }+ \text { oxaliplatin } \\
\text { Capecitabine }+ \text { oxaliplatin }+ \text { cetuximab }\end{array}$ & $\begin{array}{l}12 / 37 \\
4 / 37\end{array}$ & ORR & OS, TTP, TTF & 13 \\
\hline Diaz-Rubio 2012 & $\begin{array}{l}\text { XELOX }+ \text { bevacizumab } \rightarrow \\
\text { maintenance bevacizumab }+ \text { XELOX or } \\
\text { maintenance bevacizumab }\end{array}$ & $\begin{array}{c}70 / 239 \\
0 / 241\end{array}$ & PFS & $\begin{array}{l}\text { OS, ORR, TTR, DoR, } \\
\text { safety }\end{array}$ & 14 \\
\hline Dotan 2012 & $\begin{array}{l}\text { Capecitabine }+ \text { oxaliplatin }+ \text { cetuximab }+ \text { bevacizumab } \\
\text { Capecitabine }+ \text { oxaliplatin }+ \text { cetuximab }\end{array}$ & $\begin{array}{l}0 / 12 \\
1 / 11\end{array}$ & ORR & OS, TTP & 15 \\
\hline Feliu 2010 & Capecitabine + bevacizumab & $59 / 59$ & ORR & PFS, OS, safety & 16 \\
\hline Okita 2012 & FOLFOX6 + bevacizumab & $7 / 50$ & ORR & $\begin{array}{l}\text { TTF, PFS, OS, AEs, } \\
\text { neurotoxicity }\end{array}$ & 17 \\
\hline Souglakos 2012 & $\begin{array}{l}\text { CAPIRI + bevacizumab } \\
\text { FOLFIRI + bevacizumab }\end{array}$ & $\begin{array}{l}63 / 167 \\
55 / 166\end{array}$ & PFS & OS, ORR, safety & 18 \\
\hline Tol 2009 & $\begin{array}{l}\text { Capecitabine }+ \text { oxaliplatin }+ \text { bevacizumab } \\
\text { Capecitabine }+ \text { oxaliplatin }+ \text { bevacizumab }+ \text { cetuximab }\end{array}$ & $\begin{array}{c}81 / 378 \\
0 / 377\end{array}$ & PFS & $\begin{array}{l}\text { OS, ORR, safety, QoL, } \\
\text { KRAS status/EGFR }\end{array}$ & 19 \\
\hline Arkenau 2008 & $\begin{array}{l}\text { CAPOX } \\
\text { FUFOX }\end{array}$ & $\begin{array}{l}75 / 241 \\
64 / 233\end{array}$ & PFS & ORR, OS, TTF & 20 \\
\hline Koopman 2007 & $\begin{array}{l}\text { Capecitabine } \rightarrow \text { irinotecan } \rightarrow \text { capecitabine }+ \text { oxaliplatin } \\
\text { Capecitabine }+ \text { irinotecan } \rightarrow \text { capecitabine }+ \text { oxaliplatin }\end{array}$ & $\begin{array}{l}26 / 401 \\
38 / 402\end{array}$ & OS & PFS, OS, toxicity, QoL & 21 \\
\hline Tournigand 2004 & $\begin{array}{l}\text { FOLFIRI } \rightarrow \text { FOLFOX6 } \\
\text { FOLFOX } 6 \rightarrow \text { FOLFIRI }\end{array}$ & $\begin{array}{l}19 / 109 \\
31 / 111\end{array}$ & OS & PFS, ORR, safety & 22 \\
\hline
\end{tabular}

DoR, duration of response; PFS, progression-free survival; QoL, quality of life; ORR, objective response rate; TTF, time to treatment failure; TTP, time to progression; TTR, time to response
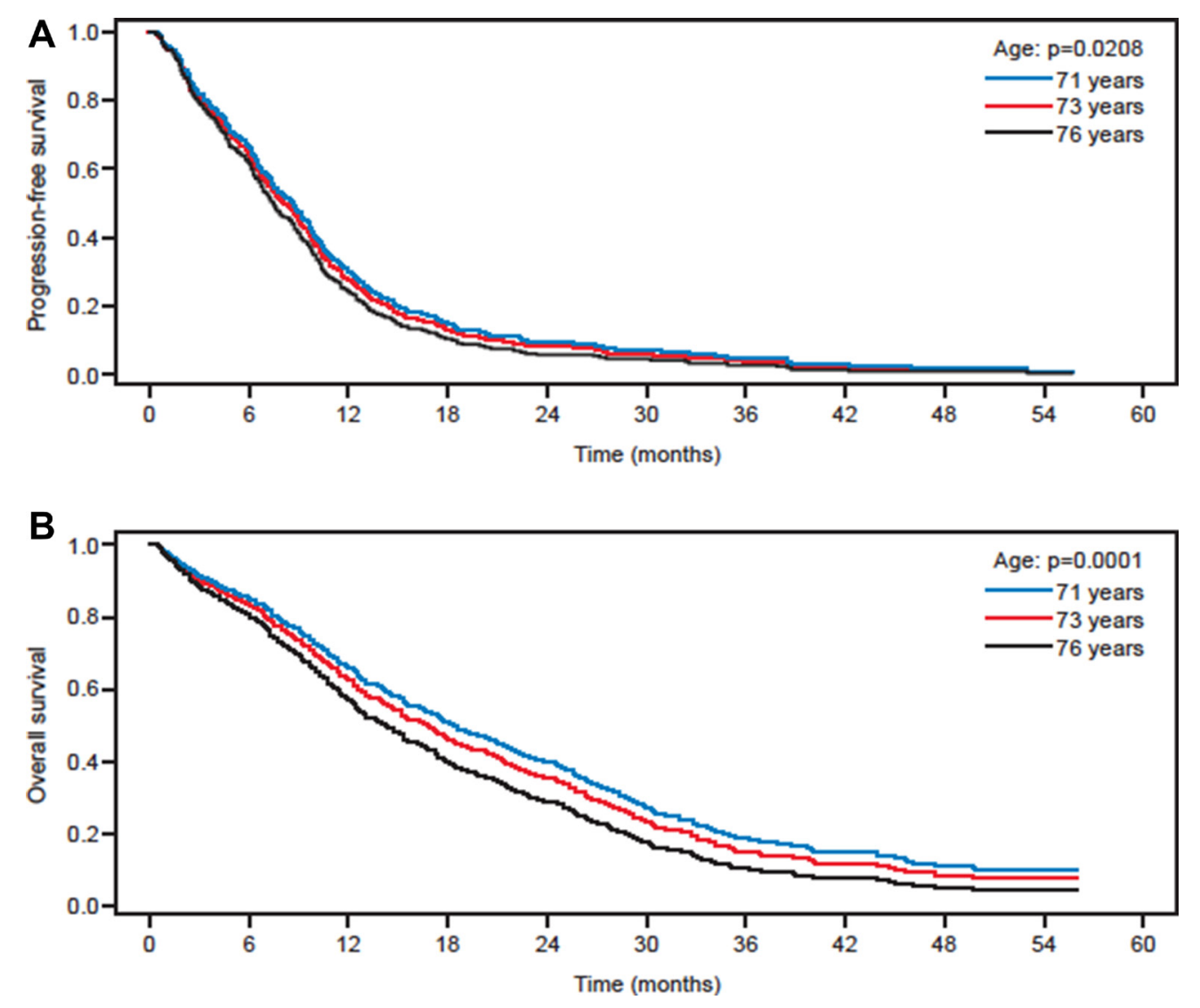

Figure 5: Effect of age in all patients on: (A) progression-free and (B) overall survival based on a Cox regression curve with age as quantitative covariate in patients $\geq 70$ years of age with mCRC. The exemplary values of predicted survival curves at 71,73 and 76 years of age correspond to the first quartile, median age and third quartile, respectively. 
chemotherapy plus bevacizumab had similar PFS as those patients $<65$ years and receiving the same treatment while, as expected, OS lessened with increased age [23].

The addition of bevacizumab to a chemotherapy regimen was well tolerated in this elderly population, with only a trend towards significance for hypertension (Table 2) in patients treated with bevacizumab; the incidence of all other adverse events was comparable with those receiving chemotherapy alone. Hence, the argument that greater toxicity is observed in elderly patients receiving bevacizumab is not supported by the findings of this meta-analysis.

The efficacy and tolerability results observed in this meta-analysis are in agreement with findings from the phase III AVEX trial, which reported a clinically significant benefit of adding bevacizumab to low doses of capecitabine $\left(2000 \mathrm{mg} / \mathrm{m}^{2} /\right.$ day $)$ in patients aged $\geq 70$ years not deemed suitable for treatment with chemotherapy doublets. Patients with a median age of 76-77 years gained a 4-month PFS benefit (HR: 0.53, 95\% CI: $0.41-0.69 ; p<0.001)$ and a clinically, but not statistically, significant OS benefit of 3.9 months (HR: 0.79 , 95\% CI: $0.57-1.09 ; p=0.182$ ) with bevacizumab plus capecitabine versus capecitabine alone [7]. Recently, data from a single-arm Japanese phase 2 trial, including 55 patients with $\mathrm{mCRC}$, were published, demonstrating that the oral fluoropyrimidine UFT combined with biweekly bevacizumab is a tolerable and effective treatment option for elderly patients [9]. Similarly, a pooled analysis of four randomised clinical studies comparing elderly with younger mCRC patients showed that the addition of bevacizumab to chemotherapy provided comparable PFS and OS benefits in medically fit older patients [24]. Furthermore, in the randomised AGITG MAX study, the improvement in PFS observed when bevacizumab was added to the existing chemotherapy regimen was similar in those patients $\geq 75$ years of age compared with younger patients [25]. However, not all studies evaluating the effect of age on mCRC treatment outcome with chemotherapy plus a monoclonal antibody have reported similar outcomes in the two age groups. For example, in a US observational cohort study (Avastin ${ }^{\circledR}$ Registry: Investigation of Effectiveness and Safety; ARIES), there were slight reductions in PFS (10.3 vs. 9.9 months) and OS (25.1 vs. 19.6 months) in mCRC patients $\geq 70$ years compared with those $<70$ years of age receiving bevacizumab and chemotherapy in the first-line setting; interestingly though, PFS (7.9 vs. 7.9 months) and OS (18.7 vs. 17.2 months) did not differ in the second-line setting when comparing the two age groups [26, 27].

There are a number of limitations of this metaanalysis at both the study and outcome level that need to be addressed. There is the risk of bias in the findings, with incomplete retrieval of clinical data from all of the identified research generating a potential bias towards those studies that have shared their data. It is also feasible that as elderly patients increase in age they might also have a poorer general prognosis and certainly have a higher probability of non-tumor-related death, which could confound the results somewhat. The primary goal of the study was to provide sufficient data both for the use of bevacizumab as well as for the use of either cetuximab or panitumumab in combination with first-line chemotherapy in elderly patients. However, we did not receive data from a sufficient number of studies/patients receiving one of these anti-EGF-receptor antibodies in combination with first-line chemotherapy. Therefore, further analyses on the use of anti-EGF-receptor based regimen in elderly patients with $\mathrm{mCRC}$ are necessary.

In conclusion, elderly patients with $\mathrm{mCRC}$ are frequently underrepresented in clinical trials. Published phase II and III clinical trials that evaluated monoclonal antibodies plus chemotherapy did not include subgroup analyses of elderly patients [32, 33, 34] or showed an unfavourable outcome of patients older than 75 years for FOLFOX plus anti-EGF-receptor antibodies [35]. A pooled analysis of studies with bevacizumab suggested a benefit for patients older than 65 years, however only PFS was superior [36]. In real-life the majority of patients with $\mathrm{mCRC}$ are older than 65 years and undertreatment in this large cohort of patients just based on age must be avoided. While each patient should be considered on an individual basis, the results of this meta-analysis suggest that the addition of bevacizumab to a first-line chemotherapy regimen improves clinical outcome in elderly patients while remaining well tolerated. Further studies are warranted with recruitment of patients of an appropriate age in clinical trials that better reflects incidence rates of the disease in the general population.

\section{MATERIALS AND METHODS}

\section{Protocol and registration}

This individual patient data based meta-analysis was planned in advance; however, the protocol has not been published and the meta-analysis has not been registered.

\section{Inclusion and exclusion criteria}

Inclusion criteria: controlled, comparator phase II or III studies that included patients aged $\geq 70$ years, with Eastern Cooperative Oncology Group Performance Status $($ ECOG PS) $\leq 1$ and previously untreated $\mathrm{mCRC}$; patients received standard first-line chemotherapy with or without a monoclonal antibody (bevacizumab, cetuximab, panitumumab [cetuximab and panitumumab only if the KRAS status was known at study start]).

Exclusion criteria: retrospective cohort studies, observational studies, previous treatment for liver metastases, off-label therapies, second-line or subsequent regimens, adjuvant therapy, combination with multiple antibodies in all treatment arms. 
Table 2: Incidence adverse events (CTC grade $\geq 3$ ) in patients $\geq 70$ years of age with $\mathbf{m C R C}$ treated with or without bevacizumab.

\begin{tabular}{|c|c|c|c|}
\hline $\begin{array}{l}\text { Adverse event, \% } \\
(95 \% \text { CI) }\end{array}$ & Bevacizumab & $\begin{array}{l}\text { No monoclonal } \\
\text { antibody }\end{array}$ & $P$-value ${ }^{\mathrm{b}}$ \\
\hline Hypertension & $6(2-15)$ & $1(0-5)$ & 0.0766 \\
\hline Nausea and vomiting & $5(2-13)$ & $14(10-19)$ & 0.0591 \\
\hline Allergic reaction & $3(1-7)$ & $1(0-5)$ & $p>0.20$ \\
\hline Hand-foot syndrome & $9(4-20)$ & $3(1-15)$ & $p>0.20$ \\
\hline Dermatological changes $^{\mathrm{a}}$ & $1(0-4)$ & $1(0-5)$ & $p>0.20$ \\
\hline Gastrointestinal perforation & $2(1-5)$ & $1(0-5)$ & $p>0.20$ \\
\hline Electrolyte imbalance & $2(1-4)$ & $1(0-5)$ & $p>0.20$ \\
\hline Fracture & $2(1-4)$ & $1(0-5)$ & $p>0.20$ \\
\hline Urological AEs ${ }^{\mathrm{b}}$ & $2(1-5)$ & $1(0-5)$ & $p>0.20$ \\
\hline Syncope & $2(1-5)$ & $1(0-5)$ & $p>0.20$ \\
\hline Diarrhoea & $11(5-21)$ & $6(1-33)$ & $p>0.20$ \\
\hline Pain $^{c}$ & $4(2-8)$ & $3(2-7)$ & $p>0.20$ \\
\hline Thrombosis, embolism, phlebitis & $5(2-13)$ & $3(1-18)$ & $p>0.20$ \\
\hline Dehydration & $2(1-5)$ & $2(1-7)$ & $p>0.20$ \\
\hline Myelosuppression & $9(3-24)$ & $6(1-24)$ & $p>0.20$ \\
\hline Infection $^{\mathrm{d}}$ & $6(3-13)$ & $9(6-13)$ & $p>0.20$ \\
\hline Weight loss/loss of appetite & $5(2-11)$ & $4(1-21)$ & $p>0.20$ \\
\hline Fatigue & $8(2-25)$ & $5(1-29)$ & $p>0.20$ \\
\hline Neuropathy & $6(2-20)$ & $5(1-33)$ & $p>0.20$ \\
\hline Gastrointestinal AEs $\mathrm{s}^{\mathrm{e}}$ & $4(2-9)$ & $3(1-18)$ & $p>0.20$ \\
\hline Bleeding & $1(0-3)$ & $3(1-14)$ & $p>0.20$ \\
\hline Dyspnoea & $3(1-6)$ & $31-8)$ & $p>0.20$ \\
\hline Febrile neutropenia & $2(1-4)$ & $3(0-23)$ & $p>0.20$ \\
\hline Cardiac events ${ }^{\mathrm{f}}$ & $3(2-7)$ & $4(2-8)$ & $p>0.20$ \\
\hline
\end{tabular}

${ }^{\mathrm{a} A c n e}$, nail changes, other (not specified by authors of original study/publication).

bIncontinence, urinary retention, elevated creatinine.

${ }^{c}$ Musculoskeletal, visceral, tumour pain.

'Includes mucositis, sepsis.

'Xerostomia, constipation, ileus, malabsorption, ulcer, other colon events (not specified by authors of original study/ publication).

IIschaemia, transient ischaemic event, angina pectoris, supraventricular tachycardia, other (not specified by authors of original study/publication). The events are sorted by descending $p$-value.

\section{Search strategy and data extraction}

PubMed and the Cochrane Library were searched using the following terms: (colorectal [title] AND cancer [title] AND bevacizumab [title]); (colorectal [title] AND cancer [title] AND cetuximab [title]); and (colorectal [title] AND cancer [title] AND panitumumab [title]). The Cochrane Library was searched using the following terms: (colorectal [Title, Abstract, Keywords] AND cancer [Title, Abstract, Keywords] AND bevacizumab [Title, Abstract, Keywords]); (colorectal [Title, Abstract, Keywords] AND cancer [Title, Abstract, Keywords] AND cetuximab [Title, Abstract, Keywords]); and (colorectal
[Title, Abstract, Keywords] AND cancer [Title, Abstract, Keywords] AND panitumumab [Title, Abstract, Keywords]).

The PubMed and the Cochrane Library searches were performed on 29 April 2013 and only studies published up until this date were included in this metaanalysis. Abstract databases and congress websites were not searched or included in this analysis.

The search results were screened for relevance by reading the titles and abstracts, and any duplicates were removed; potentially relevant articles were read by two independent reviewers to identify those studies that satisfied the inclusion and exclusion criteria. 


\section{Data acquisition}

Authors of each of the identified articles were contacted to request information on patients $\geq 70$ years of age in the respective studies. The requested information included data on progression-free survival (PFS) and overall survival (OS), together with individual patient data on treatment regimes, age and sex. In addition to this, data were also collected on any potential signs of toxicity such as myelosuppression, electrolyte imbalance, fatigue, bleeding, nausea and vomiting, gastrointestinal adverse events (AEs; xerostomia, constipation, ileus, malabsorption, ulcers, and other colon event), weight loss/ loss of appetite, dehydration, febrile neutropenia due to myelosuppression, infection (including mucositis, sepsis), cardiovascular events (ischaemia, transient ischaemic event, other), hypertension, urological AEs (incontinence, urinary retention, elevated creatinine), dyspnoea, dermatological changes (acne, nail changes, other), handfoot syndrome, thrombosis/embolism/phlebitis, allergic reaction, neuropathy, pain (muscloskeletal, visceral, tumor pain), fracture and other signs.

\section{Statistical analysis}

\section{Synthesis of results}

The primary aim was the assessment of both PFS and OS in patients $\geq 70$ years of age treated with chemotherapy with or without a monoclonal antibody. As for potential confounding factors, this comparison was done using a Cox proportional hazards model to account for the heterogeneity between studies with a gammafrailty modelling approach with one degree of freedom. Survival curves are compared with Kaplan-Meier curves in the single study populations to illustrate heterogeneity.

\section{Risk of bias across studies}

Risk of selection and publication bias was assessed by funnel plots comparing correlations of PFS and OS for each treatment group with sample size.

\section{Additional analyses}

Besides the primary analysis of survival data for comparison of the treatment groups, potential toxicity markers (as described earlier) and sex (categorical factor) and age (continuous covariate) were analysed by univariate and multivariable analyses using a stepwise backward Cox regression model for PFS and OS including, again, a frailty term. In addition, Forest plots were generated for estimation of PFS and OS at 1,2, 3 and 4 years using a $\log -\log$ transformation to estimate confidence intervals and summarise across study sites. Graphical illustrations of the predicted survival curves of univariate Cox regression discriminating between factor groups and showing typical levels for continuous covariates are presented. Overall estimations using Cox regression with a 95\% confidence interval (CI) of the hazard ratio (HR) are reported.

The incidences of potential toxicity markers included in the dataset were evaluated for treatment arms with and without monoclonal antibodies. These incidences were summarised by calculating overall proportions using a DerSimonian and Laird random effect model on logit scale. A two-sided Q-test was used to compare incidences in patients treated with and without monoclonal antibodies and this analysis was illustrated using Forest plots.

In addition to these main analyses, standard descriptive analyses (median, range, boxplots, frequencies) were used to illustrate the clinical characteristics of the dataset.

All statistical tests were two-sided and used a significance level of a $=5 \%$. The statistical analysis was performed with R 3.2.3 software (R Foundation for Statistical Computing, Vienna, Austria) using, especially, the survival and meta packages.

\section{Abbreviations}

mCRC, metastatic colorectal cancer; OS, overall survival; PFS, progression-free survival.

\section{Author contributions}

Study concept and design: Christine Koch, Joerg Trojan. Acquisition of data: Christine Koch, Anna M. Schwing, Eva Herrmann, Markus Borner, Eduardo Diaz-Rubio, Efrat Dotan, Jaime Feliu, Natsuko Okita, John Souglakos, Hendrik T. Arkenau, Rainer Porschen, Miriam Koopman, Cornelis JA Punt, Aimery de Gramont, Christophe Tournigand, Stefan Zeuzem, Joerg Trojan; Analysis and interpretation of data: Christine Koch, Anna M. Schwing, Eva Herrmann, Joerg Trojan; Drafting of the manuscript: Christine Koch, Joerg Trojan; Statistical analysis: Eva Herrmann; Final approval: All of the authors; Agreement to be accountable for all aspects of the work: All of the authors.

\section{CONFLICTS OF INTEREST}

NO received research funding (for the institution) by Novartis Pharma, Teijin Pharma, Otsuka Pharmaceuticals and Taiho Pharma. JS received research grants from Amgen, Sanofi and Roche and acted as medical advisor for Roche Hellas. JF received advisory fees from Amgen, Bayer, Roche, Lilly, Sanofi and Syrtex. RP received research grants from German Cancer Society and lecturing and advisory fees from Falk, Roche, Sanofi and Lillly. ED-R received research funding (for the institution) from Roche, Merck-Serono, Amgen and AstraZeneca and advisory fees from Roche, Merck Serono, Amgen, Bayer, Sanofi, MSD, Servier and Genomica. ED received 
research support to the institution from Oncomed, Bayer, Pfizer and Biocompatibles. JT received advisory fees from Amgen, Merck Serono, Lilly and Roche. The other authors declare no conflicts of interests.

\section{FUNDING}

Editorial support was provided by Miller Medical Communications Ltd, funded by Roche Pharma, Germany.

\section{REFERENCES}

1. Globocan 2012. Estimated cancer incidence, mortality and prevalence worldwide 2012. http://globocan.iarc.fr/Default. aspx [accessed 22 February 2017].

2. Robert Koch Institute. www.krebsdaten.de [accessed 22 February 2017].

3. Goldberg RM, Tabah-Fisch I, Bleiberg H, de Gramont A, Tournigand C, Andre T, Rothenberg ML, Green E, Sargent DJ. Pooled analysis of safety and efficacy of oxaliplatin plus fluorouracil/leucovorin administered bimonthly in elderly patients with colorectal cancer. J Clin Oncol 2006; 24:4085-4091.

4. Hutchins LF, Unger JM, Crowley JJ, Coltman CA Jr, Albain KS. Underrepresentation of patients 65 years of age or older in cancer-treatment trials. N Engl J Med. 1999; 341:2061-67.

5. Labianca R, Nordlinger B, Beretta GD, Brouquet A, Cervantes A, and ESMO Guidelines Working Group. Primary colon cancer: ESMO Clinical Practice Guidelines for diagnosis, adjuvant treatment and follow-up. Ann Oncol. 2010; 21:v70-77.

6. Yee KW, Pater JL, Pho L, Zee B, Siu LL. Enrollment of older patients in cancer treatment trials in Canada: why is age a barrier? J Clin Oncol. 2003; 21:1618-23.

7. Cunningham D, Lang I, Marcuello E, Lorusso V, Ocvirk J, Shin DB, Jonker D, Osborne S, Andre N, Waterkamp D, Saunders MP, and AVEX study investigators. Bevacizumab plus capecitabine versus capecitabine alone in elderly patients with previously untreated metastatic colorectal cancer (AVEX): an open-label, randomised phase 3 trial. Lancet Oncol. 2013; 14:1077-85.

8. Feliu J, Salud A, Safont MJ, García-Girón C, Aparicio J, Vera R, Serra O, Casado E, Jorge M, Escudero P, Bosch C, Bohn U, Pérez-Carrión R, et al. First-line bevacizumab and capecitabine-oxaliplatin in elderly patients with $\mathrm{mCRC}$ : GEMCAD phase II BECOX study. Br J Cancer. 2014; 111:241-48

9. Nishina T, Moriwaki T, Shimada M, Higashijima J, Sakai Y, Masuishi T, Ozeki M, Amagai K, Negoro Y, Indo S, Denda T, Sato M, Yamamoto Y, et al. Uracil-Tegafur and Oral Leucovorin Combined With Bevacizumab in Elderly Patients (Aged $\geq 75$ Years) With Metastatic Colorectal Cancer: A Multicenter, Phase II Trial (Joint Study of Bevacizumab, Oral Leucovorin, and Uracil-Tegafur in
Elderly Patients [J-BLUE] Study). Clin Colorectal Cancer. 2016; 15:236-42.

10. Wildiers H, Heeren P, Puts M, Topinkova E, JanssenHeijnen ML, Extermann M, Falandry C, Artz A, Brain E, Colloca G, Flamaing J, Karnakis T, Kenis C, et al. International Society of Geriatric Oncology consensus on geriatric assessment in older patients with cancer. J Clin Oncol. 2014; 32:2595-603.

11. Puts MT, Santos B, Hardt J, Monette J, Girre V, Atenafu EG, Springall E, Alibhai SM. An update on a systematic review of the use of geriatric assessment for older adults in oncology. Ann Oncol. 2014; 25:307-15.

12. Van Cutsem E, Cervantes A, Adam R, Sobrero A, Van Krieken JH, Aderka D, Aranda Aguilar E, Bardelli A, Benson A, Bodoky G, Ciardiello F, D'Hoore A, Diaz-Rubio E, et al. ESMO consensus guidelines for the management of patients with metastatic colorectal cancer. Ann Oncol. 2016; 27:1386-422.

13. Borner M, Koeberle D, Von Moos R, Saletti P, Rauch D, Hess V, Trojan A, Helbling D, Pestalozzi B, Caspar C, Ruhstaller T, Roth A, Kappeler A, et al, and Swiss Group for Clinical Cancer Research (SAKK), Bern, Switzerland. Adding cetuximab to capecitabine plus oxaliplatin (XELOX) in first-line treatment of metastatic colorectal cancer: a randomized phase II trial of the Swiss Group for Clinical Cancer Research SAKK. Ann Oncol. 2008; 19:1288-92.

14. Díaz-Rubio E, Pietrantonio F, de Braud F. Continuing single-agent bevacizumab as maintenance therapy after induction XELOX (or FOLFOX) plus bevacizumab in firstline treatment of metastatic colorectal cancer. Oncologist. 2012; 17:1426-28.

15. Dotan E, Meropol NJ, Burtness B, Denlinger CS, Lee J, Mintzer D, Zhu F, Ruth K, Tuttle H, Sylvester J, Cohen SJ. A phase II study of capecitabine, oxaliplatin, and cetuximab with or without bevacizumab as frontline therapy for metastatic colorectal cancer. A Fox Chase extramural research study. J Gastrointest Cancer. 2012; 43:562-69.

16. Feliu J, Safont MJ, Salud A, Losa F, García-Girón C, Bosch C, Escudero P, López R, Madroñal C, Bolaños M, Gil M, Llombart A, Castro-Carpeño J, González-Barón M. Capecitabine and bevacizumab as first-line treatment in elderly patients with metastatic colorectal cancer. Br J Cancer. 2010; 102:1468-73.

17. Okita NT, Esaki T, Baba E, Sakai D, Tokunaga S, Takiuchi H, Mizunuma N, Nagashima K, Kato K. A multicenter phase II study of the stop-and-go modified FOLFOX6 with bevacizumab for first-line treatment of patients with metastatic colorectal cancer. Invest New Drugs. 2012; 30:2026-31.

18. Souglakos J, Ziras N, Kakolyris S, Boukovinas I, Kentepozidis N, Makrantonakis P, Xynogalos S, Christophyllakis C, Kouroussis C, Vamvakas L, Georgoulias V, Polyzos A. Randomised phase-II trial of CAPIRI (capecitabine, irinotecan) plus bevacizumab vs FOLFIRI (folinic acid, 5-fluorouracil, irinotecan) plus bevacizumab as first-line treatment of patients with 
unresectable/metastatic colorectal cancer (mCRC). Br J Cancer. 2012; 106:453-59.

19. Tol J, Koopman M, Cats A, Rodenburg CJ, Creemers GJ, Schrama JG, Erdkamp FL, Vos AH, van Groeningen CJ, Sinnige HA, Richel DJ, Voest EE, Dijkstra JR, et al. Chemotherapy, bevacizumab, and cetuximab in metastatic colorectal cancer. N Engl J Med. 2009; 360:563-72.

20. Arkenau HT, Graeven U, Kubicka S, Grothey A, EnglischFritz C, Kretzschmar A, Greil R, Freier W, Seufferlein T, Hinke A, Schmoll HJ, Schmiegel W, Porschen R, and AIO Colorectal Study Group. Oxaliplatin in combination with 5-fluorouracil/leucovorin or capecitabine in elderly patients with metastatic colorectal cancer. Clin Colorectal Cancer. 2008; 7:60-64.

21. Koopman M, Antonini NF, Douma J, Wals J, Honkoop AH, Erdkamp FL, de Jong RS, Rodenburg CJ, Vreugdenhil G, Loosveld OJ, van Bochove A, Sinnige HA, Creemers GJ, et al. Sequential versus combination chemotherapy with capecitabine, irinotecan, and oxaliplatin in advanced colorectal cancer (CAIRO): a phase III randomised controlled trial. Lancet. 2007; 370:135-42.

22. Tournigand C, André T, Achille E, Lledo G, Flesh M, MeryMignard D, Quinaux E, Couteau C, Buyse M, Ganem G, Landi B, Colin P, Louvet C, de Gramont A. FOLFIRI followed by FOLFOX6 or the reverse sequence in advanced colorectal cancer: a randomized GERCOR study. J Clin Oncol. 2004; 22:229-37.

23. Kozloff MF, Berlin J, Flynn PJ, Kabbinavar F, Ashby M, Dong W, Sing AP, Grothey A. Clinical outcomes in elderly patients with metastatic colorectal cancer receiving bevacizumab and chemotherapy: results from the BRiTE observational cohort study. Oncology. 2010; 78:329-39.

24. Cassidy J, Saltz LB, Giantonio BJ, Kabbinavar FF, Hurwitz HI, Rohr UP. Effect of bevacizumab in older patients with metastatic colorectal cancer: pooled analysis of four randomized studies. J Cancer Res Clin Oncol. 2010; 136:737-43.

25. Price TJ, Zannino D, Wilson K, Simes RJ, Cassidy J, Van Hazel GA, Robinson BA, Broad A, Ganju V, Ackland SP, Tebbutt NC. Bevacizumab is equally effective and no more toxic in elderly patients with advanced colorectal cancer: a subgroup analysis from the AGITG MAX trial: an international randomised controlled trial of Capecitabine, Bevacizumab and Mitomycin C. Ann Oncol. 2012; 23:1531-36.

26. Hurwitz HI, Bekaii-Saab TS, Bendell JC, Cohn AL, Kozloff M, Roach N, Mun Y, Fish S, Flick ED, Grothey A, and ARIES Study Investigators. Safety and effectiveness of bevacizumab treatment for metastatic colorectal cancer: final results from the Avastin(®) Registry - Investigation of Effectiveness and Safety (ARIES) observational cohort study. Clin Oncol (R Coll Radiol). 2014; 26:323-32.

27. Kozloff M, Bekaii-Saab TS, Bendell JC, Cohn AL, Hurwitz H, Roach N, Tezcan H, Fish S, Flick ED, Mun Y, Dalal D, Grothey A. Effectiveness of first- or second-line bevacizumab (BV) treatment (tx) in elderly patients (pts) with metastatic colorectal cancer (mCRC) in ARIES, an observational cohort study (OCS). J Clin Oncol. 2011; 29:3625.

28. Moth EB, Vardy J, Blinman P. Decision-making in geriatric oncology: systemic treatment considerations for older adults with colon cancer. Expert Rev Gastroenterol Hepatol. 2016; 10:1321-40.

29. Modest DP, Ricard I, Heinemann V, Hegewisch-Becker S, Schmiegel W, Porschen R, Stintzing S, Graeven U, Arnold D, von Weikersthal LF, Giessen-Jung C, Stahler A, Schmoll HJ, et al. Outcome according to KRAS-, NRASand BRAF-mutation as well as KRAS mutation variants: pooled analysis of five randomized trials in metastatic colorectal cancer by the AIO colorectal cancer study group. Ann Oncol. 2016; 27:1746-53.

30. Arnold D, Lueza B, Douillard JY, Peeters M, Lenz HJ, Venook A, Heinemann V, Van Cutsem E, Pignon JP, Tabernero J, Cervantes A, Ciardiello F. Prognostic and predictive value of primary tumour side in patients with RAS wild-type metastatic colorectal cancer treated with chemotherapy and EGFR directed antibodies in six randomised trials. Ann Oncol. 2017; 28:1713-29.

31. Nakayama I, Shinozaki E, Matsushima T, Wakatsuki T, Ogura M, Ichimura T, Ozaka M, Takahari D, Suenaga M, Chin K, Mizunuma N, Yamaguchi K. Retrospective study of RAS/ PIK3CA/BRAF tumor mutations as predictors of response to first-line chemotherapy with bevacizumab in metastatic colorectal cancer patients. BMC Cancer. 2017; 17:38.

32. Saltz LB, Clarke S, Díaz-Rubio E, Scheithauer W, Figer A, Wong R, Koski S, Lichinitser M, Yang TS, Rivera F, Couture F, Sirzén F, Cassidy J. Bevacizumab in combination with oxaliplatin-based chemotherapy as first-line therapy in metastatic colorectal cancer: a randomized phase III study. J Clin Oncol. 2008; 26:2013-19.

33. Hurwitz H, Fehrenbacher L, Novotny W, Cartwright T, Hainsworth J, Heim W, Berlin J, Baron A, Griffing S, Holmgren E, Ferrara N, Fyfe G, Rogers B, et al. Bevacizumab plus irinotecan, fluorouracil, and leucovorin for metastatic colorectal cancer. N Engl J Med. 2004; 350:2335-42.

34. Van Cutsem E, Köhne CH, Hitre E, Zaluski J, Chang Chien CR, Makhson A, D’Haens G, Pintér T, Lim R, Bodoky G, Roh JK, Folprecht G, Ruff P, et al. Cetuximab and chemotherapy as initial treatment for metastatic colorectal cancer. N Engl J Med. 2009; 360:1408-17.

35. Douillard JY, Siena S, Cassidy J, Tabernero J, Burkes R, Barugel M, Humblet Y, Bodoky G, Cunningham D, Jassem J, Rivera F, Kocákova I, Ruff P, et al. Final results from PRIME: randomized phase III study of panitumumab with FOLFOX4 for first-line treatment of metastatic colorectal cancer. Ann Oncol. 2014; 25:1346-55.

36. Hurwitz HI, Tebbutt NC, Kabbinavar F, Giantonio BJ, Guan ZZ, Mitchell L, Waterkamp D, Tabernero J. Efficacy and safety of bevacizumab in metastatic colorectal cancer: pooled analysis from seven randomized controlled trials. Oncologist. 2013; 18:1004-12. 